\title{
Flexure of the Indian plate and intraplate earthquakes
}

\author{
Roger Bilham, Rebecca Bendick and Kali Wallace \\ CIRES and Department of Geological Sciences, University of Colorado, Boulder CO 80309-0399.
}

\begin{abstract}
The flexural bulge in central India resulting from India's collision with Tibet has a wavelength of approximately $670 \mathrm{~km}$. It is manifest topographically and in the free-air gravity anomaly and the geoid. Calculations of the stress distribution within a flexed Indian plate reveal spatial variations throughout the depth of the plate and also a function of distance from the Himalaya. The wavelength (and therefore local gradient) of stress variation is a function of the effective elastic thickness of the plate, estimates of which have been proposed to lie in the range $40-120 \mathrm{~km}$. The imposition of this stress field on the northward moving Indian plate appears fundamental to explaining the current distribution of intraplate earthquakes and their mechanisms. The current study highlights an outer trough south of the flexural bulge in central India where surface stresses are double the contiguous compressional stresses to the north and south. The Bhuj, Latur and Koyna earthquakes and numerous other recent reverse faulting events occurred in this compressional setting. The N/S spatial gradient of stress exceeds 2 bars $/ \mathrm{km}$ near the flexural bulge. The overall flexural stress distribution provides a physical basis for earthquake hazard mapping and suggests that areas of central India where no historic earthquakes are recorded may yet be the locus of future damaging events.
\end{abstract}

\section{Introduction}

Numerous earthquakes occur in the interior of the Indian plate, unlike the adjoining Arabian plate (figure 1). The number of damaging events occurring in and on the margins of India has increased significantly in the past 100 years, and doubled in the past 40 years (Bilham and Gaur 2000). An increase in the decadal number of deaths from earthquakes is a worldwide phenomenon driven by increased urban populations and by recent changes in urban construzction methods (Bilham 1988). Yet to some observers the recent increase in fatal earthquakes in India appears to exceed the global average. This recent increase in fatalities from earthquakes is almost entirely attributable to intraplate events.

Earthquakes within the Indian continent are not driven by significant contraction of the Indian plate. GPS measurements in the past decade suggest that deformation is less than $3 \pm 2 \mathrm{~mm}$ /year (Paul et al 2001) across the stable Indian craton.
The recent intraplate events in India did not produce significant crustal shortening (table 1), except near the Shillong plateau where $\approx 1.6 \mathrm{~km}$ of intraplate contraction has raised the plateau to its present level (Bilham and England 2001). This region will be ignored in the present study in that it lies close to the NE edge of the Indian plate where stresses from the Himalaya and IndoBurman ranges are presumably dissimilar to those in the interior. Stein et al (2002) have suggested that the Bhuj region may also be anomalous given its location near the western edge of India. They invoke a hitherto unidentified "flake" breaking off the edge of the plate near the Makran triple junction driven by stresses originating in the Sulaiman range of Baluchistan and Pakistan. The presence of this flake is neither supported nor denied by currently available seismic, geologic, topographic, or crustal deformation data.

In previous explanations for Indian intraplate seismicity, an underlying premise has been that stresses within the Indian plate (Gowd et al 1992)

Keywords. Mid-plate seismicity; flexure; continental earthquakes; continental erosion; flexural bulge; India. 

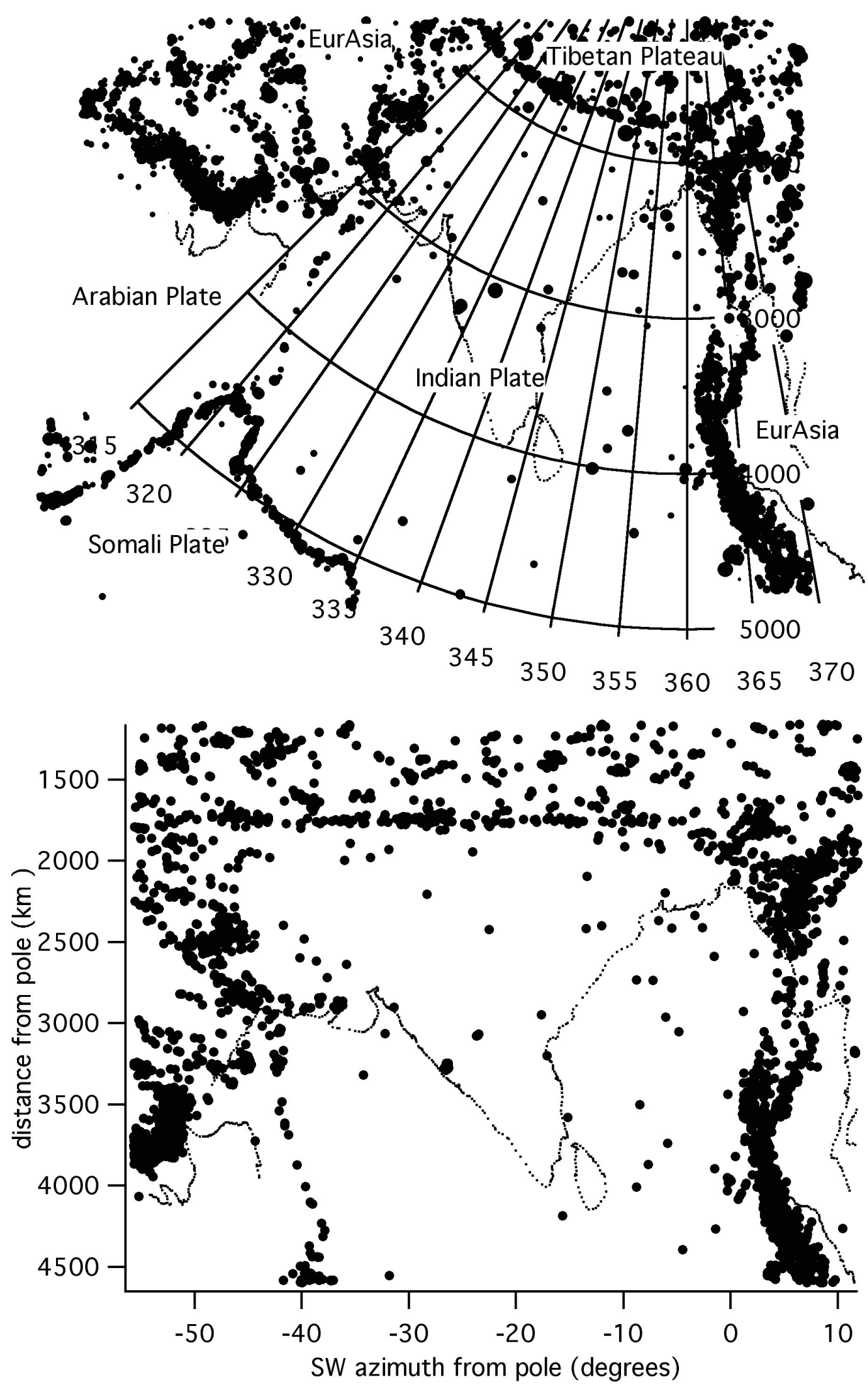

Figure 1. Earthquakes in India and neighbouring plates 1964-2001 (Engdahl et al 1997), and 1900-1964 (Triep and Sykes 1997). The upper plot is a rectilinear projection. The lower plot is a polar plot, plotted as a function of distance vs. radial angle from due south of a pole $\left(90^{\circ} \mathrm{E}, 49.5^{\circ} \mathrm{N}\right)$ at the centre of the small circle that defines the Himalayan arc. 
Table 1. Recent damaging intraplate earthquakes. The Udaypur earthquake is included in this list since it occurred at the base of the Indian plate.

\begin{tabular}{lll|llr}
\hline 1967 December 10 & 17.37 & 73.75 & Koyna & 6.5 & 177 \\
\hline 1970 March 23 & 21.7 & 73 & Broach & 5.4 & 30 \\
\hline 1975 January 19 & 32.38 & 78.49 & Kinnaur & 6.2 & 60 \\
\hline 1988 August 06 & 25.13 & 95.15 & Manipur & 6.6 & 35 \\
\hline 1988 August 21 & 26.72 & 86.63 & Udaypur & 6.4 & 6500 \\
\hline 1993 September 30 & 18.07 & 76.62 & Latur & 6.3 & 7610 \\
\hline 1997 May 22 & 23.08 & 80.06 & Jabalpur & 6 & 39 \\
\hline 2001 January 26 & 23.4 & 70.3 & Bhuj & 7.6 & 19500 \\
\hline
\end{tabular}

are high as a result of the Indo-Asian collision and that earthquakes occur within regions of rheological weakness. Any elastic weakness in an otherwise homogeneous medium has the effect of concentrating applied stress within the region of weakness (King and Bilham 1973). Thus ancient rift zones (Jain et al 1995) have been invoked as "stress concentrators" within the Indian plate focusing the approximately NE-directed compressional stress associated with Indo-Asia collision (Kenner 2001). This explanation for mid-plate earthquakes views the prevailing stress field as a stress-reservoir that is slowly being mined by earthquakes at random locations where stresses are instantaneously close to failure, or where failure conditions are perturbed by artificial processes such as the construction of large dams.

These explanations are somewhat ad hoc since they do not provide a mechanism for continuing seismicity. The data in figure 2 are from a short time interval compared to the average time between earthquakes, and although there are numerous accounts of small earthquakes occurring in India in the past 500 years these data are too incomplete to form more than general conclusions about long term earthquake occurrence. For this reason explanations for local earthquakes as a mechanism for releasing stored elastic strain energy are inconsistent with the steady occurrence of mid-plate seismicity: elastic energy, once released, will not be renewed.

The supposition that continued seismicity requires continued deformation is also not entirely rejected by the absence of observations of uplift on the Indian continent, because it is possible that this uplift occurs at rates lower than prevailing rates of erosion.

The premise that significant crustal shortening is not occurring presently within the Indian subcontinent mandates an alternate mechanism for seismic productivity. One possibility is that the cratonic stress field fluctuates in time and space as a result of forces arising at the plate boundaries.
Some stress field fluctuations are no doubt caused by slip and release of the plate along the northern collision zone in infrequent great earthquakes (Dmowska et al 1996; Taylor et al 1998). Yet earthquake stresses in the Himalaya do not appear to penetrate laterally into the Indian plate. Boundary element models of the collision process suggest that for earthquakes with rupture lengths of a few hundred kilometres, stress fluctuations during the earthquake cycle fall to low values (bars) in the northern Gangetic plain, with negligible stress changes in places like Gujarat where earthquakes are abundant.

The elastic plate may also act as a stress guide, integrating the net effects of Himalayan resistance. In such a view it may be possible to change stresses within the Indian plate far from the Himalaya. Models of these stresses depend on assumptions concerning the elastic strength of the crust and its viscous coupling to the mantle. Fluctuations in the mean resistance of the Himalaya to underthrusting of India have yet to be quantified and will not be explored here.

The above explanations for intraplate seismicity focus on the horizontal stresses of the collision process. In this article we instead consider forces applied at the plate boundaries which subsequently drive deformation within the plate. These end loads and bending moments result from the bending of the Indian plate by the weight of the Himalaya and Tibet acting on its northern edge, by the bending moment of the Indian plate flexed downward beneath Tibet, and by the buckling effect of horizontal stress from convergence. This model requires no unusual propagation of forces far into an elastic medium.

The stresses in the plate resulting from flexure are static with respect to southern Tibet, but not with respect to the moving Indian crust. The important corollary is that flexural stresses vary with time within the Indian plate as it approaches Tibet at $\approx 18 \mathrm{~mm} /$ year (Wang et al 2001). Although this variation in stress is slow, the 


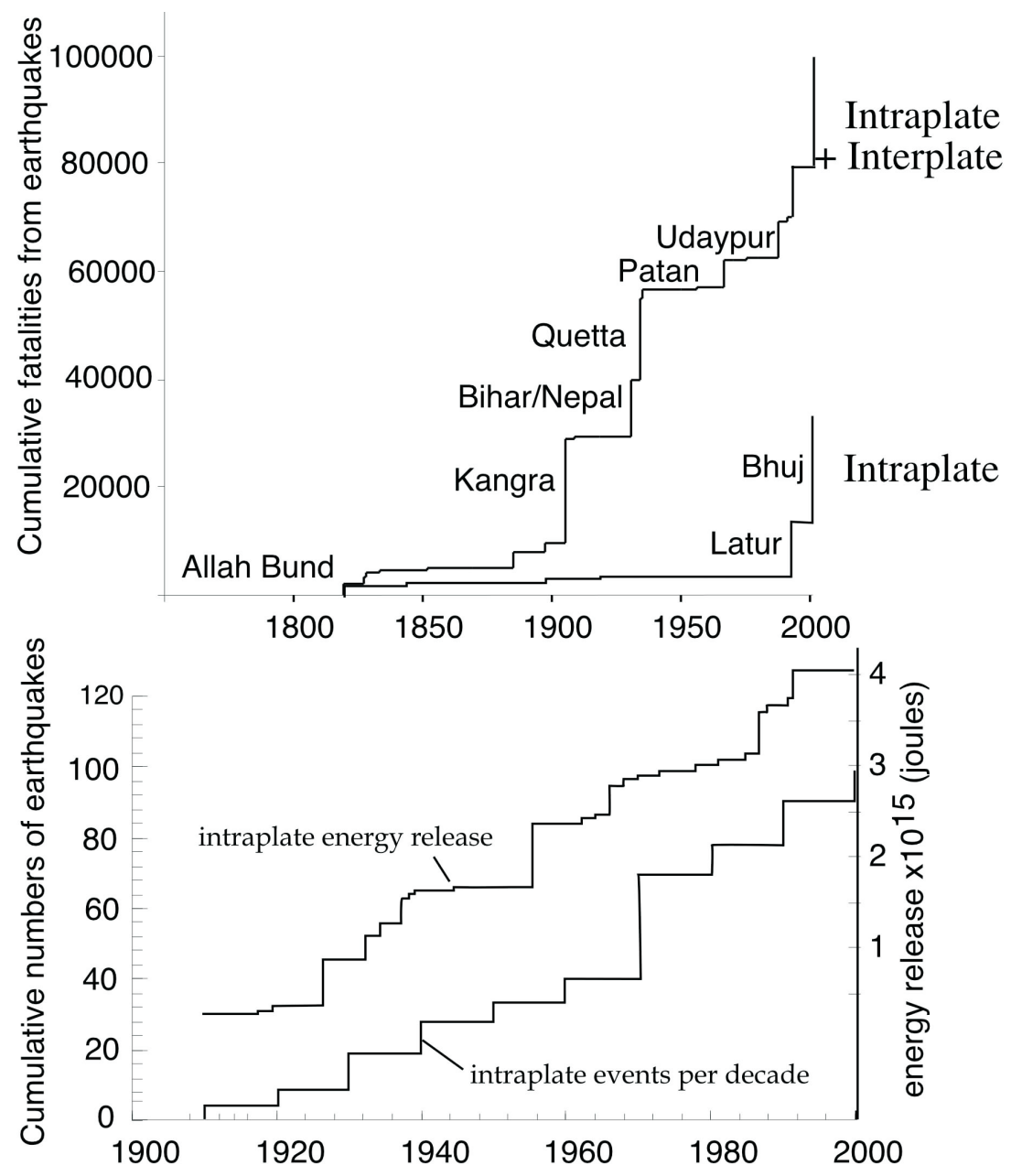

Figure 2. Deathtoll from all damaging earthquakes in and surrounding the Indian plate compared to intraplate events and intracratonic energy release. The Udaypur event occurred in the craton beneath the Nepal Himalaya. The apparent increase in decadal numbers of events after 1960 is caused by improved reporting of events following the deployment of the world-wide seismic network. Intraplate events 1900-2000 (Triep and Sykes catalog) within $1000 \mathrm{~km}$ of the Himalayan frontal thrusts. The energy release from the Bhuj 2001 event (not shown) exceeds all the energy released in the previous century.

static stress field overwhelms the largely homogenous horizontal (in plane) stress in the plate. In places the magnitude of the flexural stress field may be more than doubled, raising these parts of the Indian plate close to failure, neutralizing stresses in some locations, and reversing stress in other parts of the Indian plate toward tensile failure. We shall show that this stress distribution is largely consistent with the distribution and sense of slip of intraplate earthquakes in India.

\section{Flexure of the surface of the Indian plate}

The most obvious evidence for the flexure of the Indian plate is the burial of its ancient surface beneath the sediments of the Ganges prior to its descent beneath the Himalaya. Starting 200$400 \mathrm{~km}$ south of the Himalaya the upper surface of the Indian plate descends beneath the Ganga Plain at $2-4^{\circ}$, attaining depths of $4-6 \mathrm{~km}$ beneath the Himalayan forelands (Sastri et al 1971). The deep sediments give rise to a distinct gravity low that was noted by early investigators (Burrard 1901, 1912; Oldham 1917; Cowie 1921). On the basis of deflections of the vertical, Burrard (1901) infers the existence of a "hidden chain" of mountains parallel to the Himalaya south of the Ganges basin. The presence of this "hidden chain" was further developed by Glennie (Chart VI, 1931) using gravity data. These early investigations were effectively interpreting aspects of the Indian geoid (figure 3) that show a local low beneath the Ganges and a high beneath the Central Indian Plateau (Rapp et al 1991).

Following the development of plate tectonics it was recognized that where one plate descends below another, elastic effects cause the trailing edge of the descending plate to be flexed upward to form 


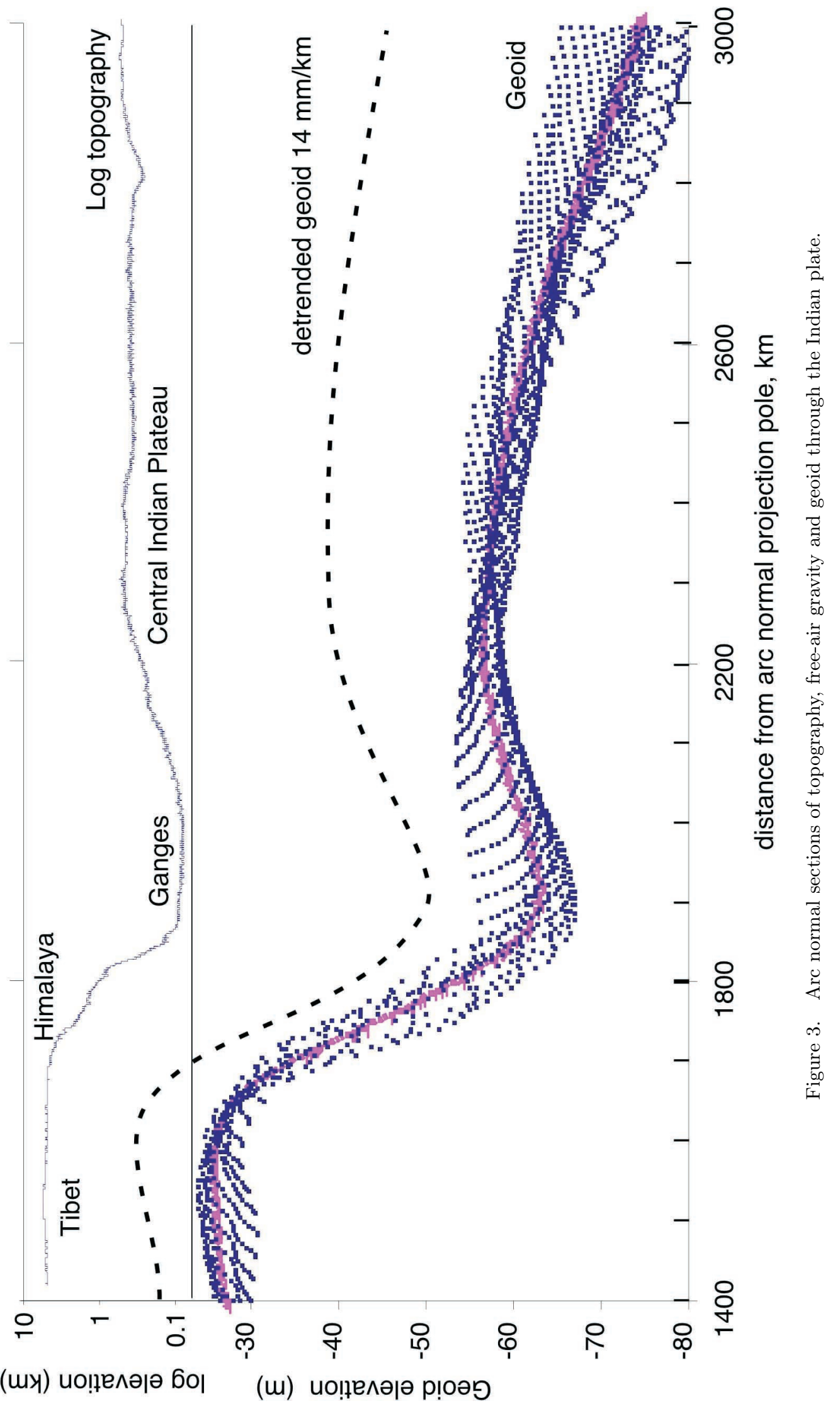


an outer rise. In oceanic plates the form of this outer rise shows clearly in bathymetric and gravity profiles. A similar flexed condition occurs in the Indian plate although the morphological signatures of the outer rise are obscured by erosion. The geometry and gravity field of the Himalaya and Ganges plain provide a quantitative basis for estimating the flexure and elastic thickness of the Indian plate (Parsons and Molnar 1976; Molnar et al 1977; Lyon-Caen and Molnar 1983, 1985; Karner and Watts 1983; Watts 2001). These methods yield estimates for the elastic thickness of the Indian plate in the range $70-120 \mathrm{~km}$.

An alternative approach to estimating the elastic thickness of the Indian plate ignores the forces applied to the plate and instead invokes the geometry of the free-air gravity field as a constraint (McKenzie and Fairhead 1997). The observed wavelength and amplitude of the gravity field requires a significantly thinner elastic thickness, with a preferred value of $37 \mathrm{~km}$. Although the gravity data are sufficiently noisy to admit a 30$60 \mathrm{~km}$ range of permissible thicknesses, Maggi et al (2000) and Jackson (2002) reason that a smaller elastic thickness is consistent with the absence of intraplate earthquakes deeper than $40 \mathrm{~km}$. They argue that because elastic conditions do not prevail below $40 \mathrm{~km}$ at seismic frequencies, a flexural bulge cannot be supported over long time scales. A $40 \mathrm{~km}$ thick elastic plate subject to end-loading stresses alone, however, would be flexed with a wavelength roughly half that which is observed in northern India.

McKenzie and Fairhead (1997) conjecture that the longer observed wavelength is supported by mantle dynamics not considered in thin elastic plate models of the Indian collision. One such mechanism has been proposed by Melosh (1978) and Melosh and Raefsky (1908). In this model, a thin elastic plate is effectively supported by dynamic flow in the upper mantle, the flexural stress distribution in the elastic plate being similar though of lower amplitude than were the entire flexural bulge supported by bending of a thick plate.

The current controversy concerning the elastic thickness of the northern Indian plate remains to be settled. In this article we shall calculate stresses in a flexed $90 \mathrm{~km}$ thick plate, with the assumption (possibly incorrect) that flexural stresses in a $45 \mathrm{~km}$ thick plate with the same flexural wavelength will be precisely half as intense.

\section{Geometry of flexure}

The Indian plate is flexed downward by the load of the Himalaya and by bending moments related to plate collision. The curvature of the Himalayan arc, and the loading of the Bengal fan and the Sulaiman and Indo-Burman ranges, add additional membrane stresses to the plate that will be ignored.

Elastic models of the flexural bulge indicate that its amplitude depends linearly on the in-plane force per unit length applied to the Indian plate. If cylindrical deformation of a thin elastic plate is assumed, the local elevation of a thin plate, $y$, overlying an inviscid fluid is given by

$$
\begin{aligned}
y=\left\{2 /\left(\alpha \beta N_{\text {cr }}\right)\left(M+N y_{0} / 2\right) \sin \beta \lambda x\right. & \\
& \left.-y_{0} \cos \beta \lambda x\right\} e^{-\alpha \lambda x}
\end{aligned}
$$

with $\alpha=\left(1-N / N_{\mathrm{cr}}\right)^{1 / 2}, \beta=\left(1+N / N_{\mathrm{cr}}\right)^{1 / 2}, \lambda=$ $(\rho g / 4 D)^{1 / 4}, D=E h^{3} / 12\left(1-\nu^{2}\right), N_{\mathrm{cr}}=4 D \lambda^{2}$ (e.g. Parsons and Molnar 1976; Warsi and Molnar 1977; Molnar et al 1977; Lyon Caen and Molnar 1983; 1985; Turcotte and Schubert 1983). $N_{\text {cr }}$ is the critical force per unit length that, if exceeded, will induce plate buckling, and $N$ is the in-plane force per unit length applied to the Indian plate. Assuming $10<N_{\text {cr }} / N<100$, Young's modulus of $1.6 \times 10^{12}$ dynes $\mathrm{cm}^{-2}$, Poisson's Ratio $=0.25$, and $y_{0}=4 \mathrm{~km}$ at $x_{0}$, we calculate that a $0.01 \mathrm{MPa}$ change in applied in-plane stress will result in an amplitude change at the crest of the bulge of approximately $2 \mathrm{~cm}$.

\section{Topographic evidence for a flexural bulge}

The location, wavelength and amplitude of the flexural bulge are not readily apparent because the ancient land surface of India has been deeply eroded. Moreover, the elevation of the hills south of the Ganges vary significantly with longitude, and although parts of central India where the flexural bulge has its greatest expression have elevations of more than $1000 \mathrm{~m}$, this is less than the elevation of many other parts of India where flexural effects are insignificant. As a consequence, the identification of the peak elevation of the flexural bulge and its distance from the Himalaya has hitherto been somewhat subjective, as the crest of the flexural bulge corresponds neither to the concordance of peak elevations, nor to average elevations in central India.

Topographic sections through the Central Indian Plateau do, however, reveal an erosion base that arches gently southward with an apparent wavelength of more than $\approx 600 \mathrm{~km}$ and an elevation of more than $250 \mathrm{~m}$ (figure 3). The arch is continuous along the curve of the Himalaya between the Indus and Ganges deltas, and approximately parallel to it at a distance of $\approx 600 \mathrm{~km}$ 


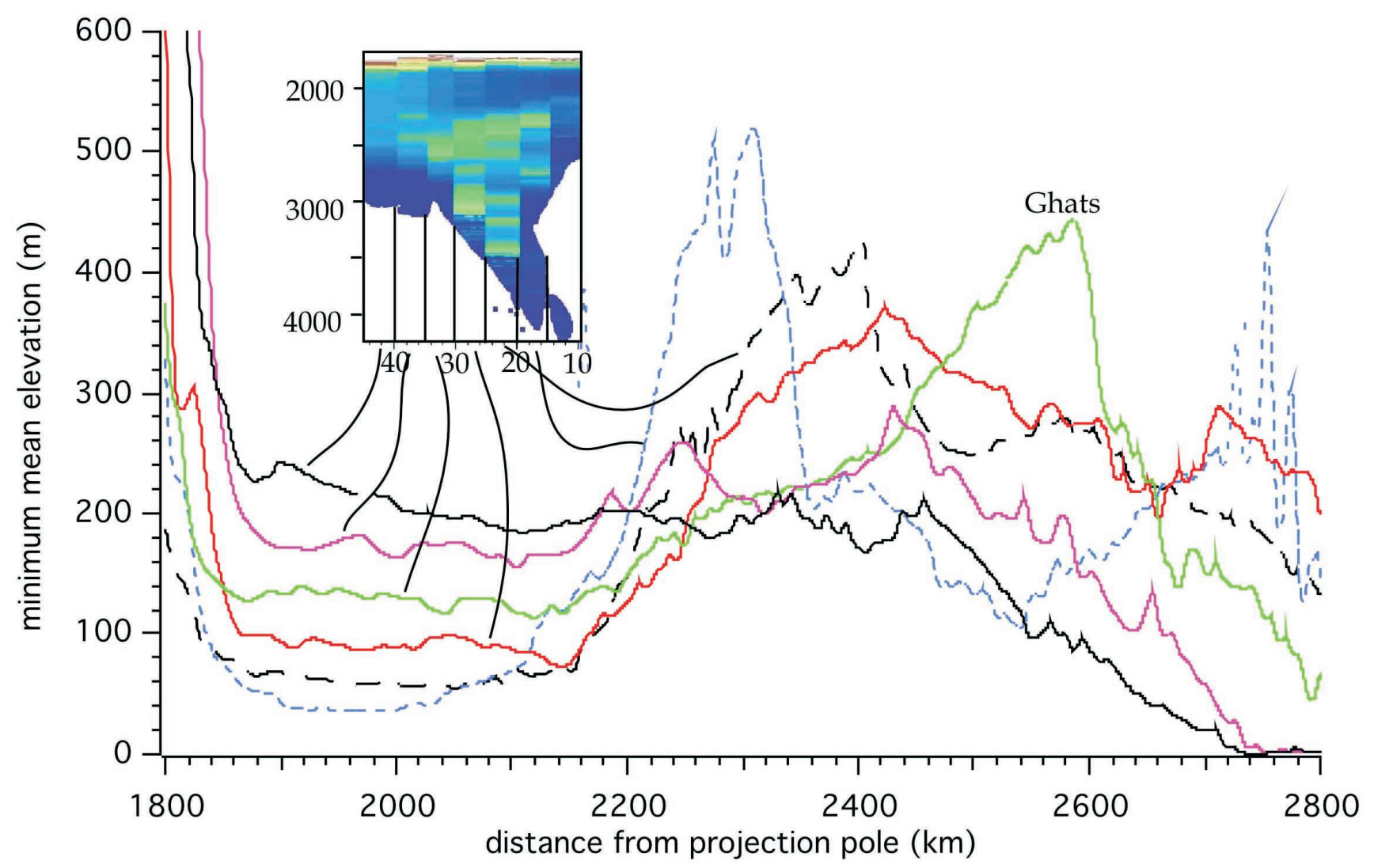

Figure 4. Arc normal swaths through the Indian plate reveal an erosion base - an arch below which rivers have yet to cut between $400 \mathrm{~km}$ and $1000 \mathrm{~km}$ from the Himalaya. The minimum elevation in $15 \mathrm{~km}$ arc-radial distances and 5 degree segments show that this is a common attribute along the arc. The apparent wavelengths of this erosion base are listed in table 2 .

from the Himalayan foothills. The absence of significant erosion below this arched region, and the prevalence of convex slopes in places flanking the arch, are suggestive of relatively recent uplift.

To reveal this topographic arch we used polar projections $\left(\right.$ pole $\left.=90 \pm 1^{\circ} \mathrm{E}, 49.5 \pm 1^{\circ} \mathrm{N}\right)$ centered on the small circle that defines the Himalayan arc (Seeber and Gornitz 1983; Bendick and Bilham 2001). In this polar projection the Indian plate subtends an arc of approximately 1 radian from the Indo-Burman margin at $\mathrm{S} 5^{\circ} \mathrm{E}$, to the Pakistan Chaman fault system at $\mathrm{S} 55^{\circ} \mathrm{W}$ (figure 4 ). The flexural bulge is readily apparent only between $\mathrm{S} 15^{\circ} \mathrm{W}$ and $\mathrm{S} 45^{\circ} \mathrm{W}$. ETOPO30 topographic data were first decimated to roughly $3 \mathrm{~km} \times 3 \mathrm{~km}$ sample areas. Next the data were binned into polarprojected segments and plotted as a function of distance from the projection pole. Further analysis was achieved after plotting the minimum elevation in sequential 10-km-long arc-normal bins within each radial segment.

It is convenient to plot both the topography and seismicity on a rectangular coordinate system with distance from pole as the vertical ordinate and polar azimuth as the horizontal ordinate (figure 5), since this results in the Himalaya appearing as a straight line (a line of latitude on the projection) with arc-normal stresses parallel to lines of longitude. The projection (e.g., figure 1b) is equivalent to a Transverse Mercator projection with equally spaced lines of latitude.

\section{The effect of eroding the flexural bulge}

An ancient range exposed to erosion would develop concave slopes facing away from a central divide, yet the erosion-base in topographic sections shown in figure 4 displays a weakly convex surface. This suggests that erosion of this surface is immature. Assuming an uplifted width of $650 \mathrm{~km}$, a convergence rate of $18 \mathrm{~mm} / \mathrm{yr}$, and a base erosion level of current sea level, the northernmost, oldest part of flexural surface has been elevated for a period of $650 / 18 \approx 36 \mathrm{Myr}$, approximately equivalent to the time since the "hard" collision of the Indian subcontinent with Tibet.

Since the mean erosion rate for this period of time in central India is not known (e.g. Goudie 1995) several possible rates were examined to investigate their effect on the flexural curve. In 


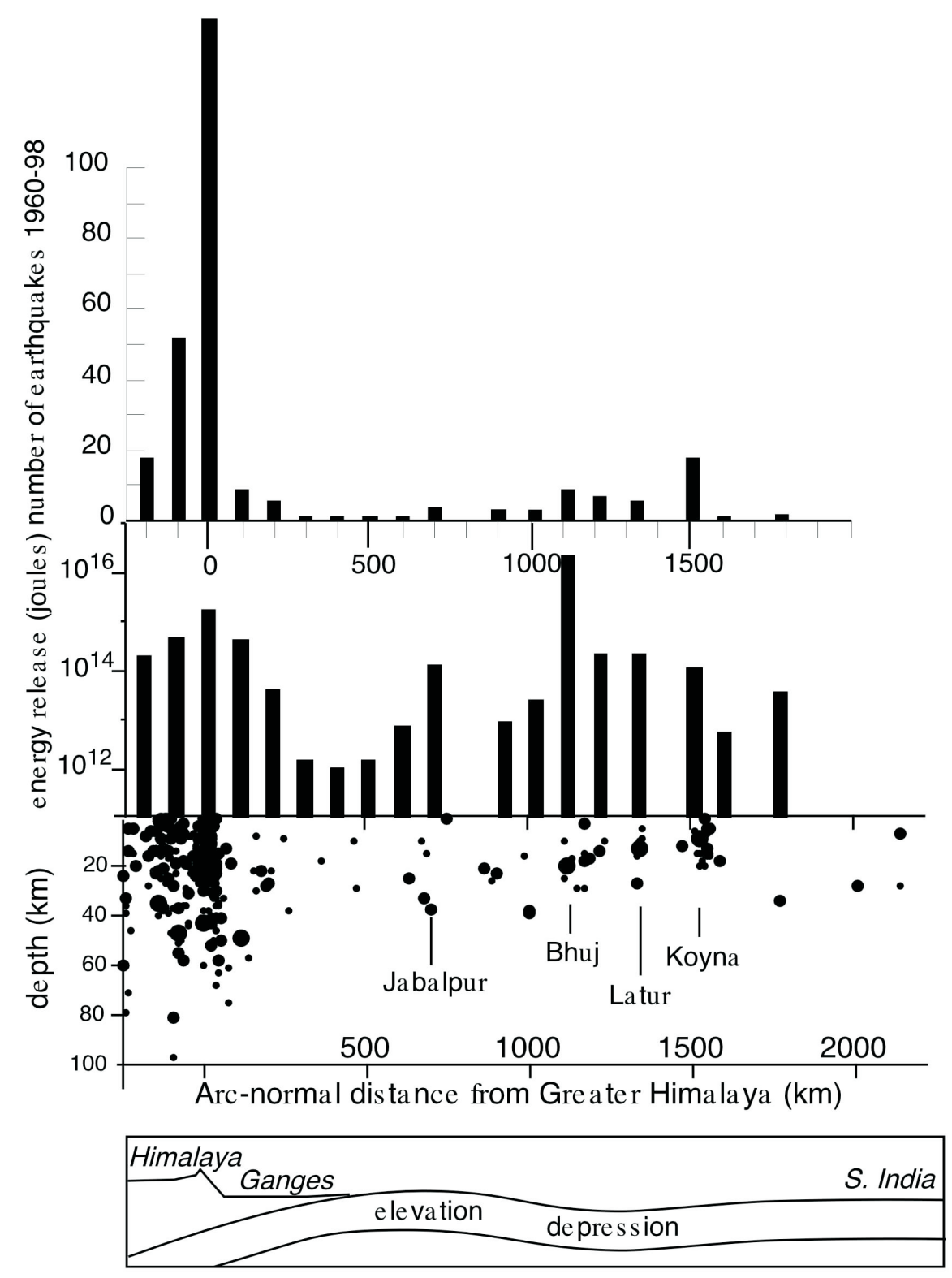

Figure 5. Seismic and structural sections through the Himalaya and Indian plate. Cumulative numbers of earthquakes since 1960, and their equivalent energy release, are binned in $100 \mathrm{~km}$ arc-normal distances. The locations of significant events are named. Note the absence of seismicity below $40 \mathrm{~km}$ in the Indian plate.

general, a faster rate of annual erosion reduces the amplitude of the bulge and shifts its position southward. A faster rate of slope-dependent erosion reduces the curvature of the bulge. The effects of a surface erosion rate of $8 \mu \mathrm{m} /$ year and slope erosion rate of $80 \mu \mathrm{m} / \mathrm{rad} /$ year are shown in figure 6. A third parameter must be adjusted to obtain a good fit between a theoretical eroded flexural curve and the observed erosion base, namely, the mean height of the pre-flexure erosion base in northern India. Values between +40 and $+150 \mathrm{~m}$ were found to give satisfactory fits.
For a fifteen degree radial swath in central India (S15W-S30W) fits to the erosion base yielded an elastic thickness $T e=90-110 \mathrm{~km}$ for a ratio of $N / N_{c r}$ of 0.1 . Fits assuming no erosion required a $10 \%$ thicker elastic thickness.

The wavelength of the eroded surface differs little from the wavelength of a non-eroded flexural bulge but its amplitude can be reduced by almost $50 \%$ depending on the prevailing mean erosion rates. Thus if erosional effects are ignored, flexural fits to the erosion base are likely to underestimate true flexural stresses by up to a factor of two. 
Table 2. Variation in apparent wavelength of erosion base along arc. The estimated "wavelength" is the apparent distance between the point of emergence and submergence of the erosion base below current sea level. The mean wavelength is $675 \mathrm{~km}$ and the wave-form in each case is asymmetric with a mean amplitude of $250 \mathrm{~m}$ (see figure 3). The mean distance of the emergence of the bulge $(424 \mathrm{~km})$, and its crest $(730 \mathrm{~km})$, are measured from the locking line (Bilham et al 1997), a line along the Himalaya, $1695 \mathrm{~km}$ from the Himalayan small-circle pole (Bendick and Bilham 2001). The frontal thrusts of the Himalaya lie approximately $100 \mathrm{~km}$ radially SW of this locking line. The flexural bulge is only discernable topographically in the central 30 degrees of the Himalayan Arc. A subjective attempt has been made in the estimates to ignore inherited topography.

\begin{tabular}{lcccc}
\hline Segment & $\begin{array}{c}\text { Wavelength } \\
(\mathrm{km})\end{array}$ & $\begin{array}{c}\text { Emergence } \\
(\mathrm{km})\end{array}$ & $\begin{array}{c}\text { Crest } \\
(\mathrm{km})\end{array}$ & $\begin{array}{c}\text { Height } \\
(\mathrm{m})\end{array}$ \\
\hline $15-20$ & 500 & 405 & 655 & 300 \\
$20-25$ & 650 & 455 & 755 & 240 \\
$25-30$ & 750 & 455 & 755 & 300 \\
$30-35$ & 800 & 405 & 805 & 250 \\
$35-40$ & 700 & 405 & 705 & 250 \\
$40-45$ & 650 & 405 & 705 & 200 \\
Mean & 675 & 424 & 730 & 257 \\
\hline
\end{tabular}

\section{Stress in a flexed elastic plate}

The longitudinal stress at any depth within a twodimensional bent elastic plate of thickness, $h$, is the sum of the applied horizontal stress per unit length $N / h$ plus a stress proportional to the bending radius and distance $w$, from the center of the bent plate.

$$
\rho=N / h+w \cdot d^{2} y / d x^{2}
$$

for $-h / 2<w<h / 2$ (positive stress indicates compression).

Stresses throughout 90, 45 and 76-km-thick plates are contoured in figure 7 . The plots are valid for plates thinner than $90 \mathrm{~km}$ only if mantle support introduces no significant change in the flexural stress distribution. This assumption remains to be tested. Common features of these plots are a small region of increased surface stress and reduced basal stress $600-1200 \mathrm{~km}$ from the Himalaya (the outer trough region), and a region of pronounced tensile surface stress and pronounced compressive basal stress in the $700 \mathrm{~km}$ south of the Himalaya (the Ganges plain). The neutral axis that in a flexed plate with no end loading would be at a depth of half the thickness of the plate, sinks within the plate only north of the flexural bulge. Models that incorporate more realistic rheologies are likely to result in a somewhat different distribution of stress and neutral axis but the essential features are unlikely to change: surface stresses near the Himalaya are all tensile, and stresses at the base of the plate near the Himalaya are all compressional. The neutral axis in this region lies approximately half-way through the plate because the flexural stresses here are large compared to in-plane. end-loading stresses $(<1 \mathrm{kbar})$.

Compressional stresses near the surface of the outer trough are 3 and 7 times larger than the stresses anywhere south of this upward flexed region. The stresses in the outer-moat exceed all plate tectonic stresses previously encountered by the plate in its northward journey across the Indian Ocean. Near Bhuj and to its southeast, stresses are compressional above depths of $50 \mathrm{~km}$ for end-loading stresses equal to 670 bars in a $90 \mathrm{~km}$ thick plate and above $35 \mathrm{~km}$ in a $45 \mathrm{~km}$ thick plate, but the neutral axis rises to $30 \mathrm{~km}$ for end-loading stresses of only 300 bars. Deep reverse faulting $(35 \mathrm{~km})$ in the Bhuj earthquake suggests that in-plane end-loading stresses must exceed 500 bars.

\subsection{Seismicity}

The absence of earthquakes below $40 \mathrm{~km}$ depth in the Indian plate (figure 5) except near the Himalaya does not support the notion that the elastic thickness of the Indian plate exceeds $40 \mathrm{~km}$, as suggested by the above flexural calculations based on end-loading forces. The following discussion on the observed seismicity is thus based on a $40 \mathrm{~km}$ thick elastic crust supported by dynamic flow in the Earth's mantle.

The bent plate north of the flexural bulge will have a neutral axis at a depth that is close to half the thickness of the plate, perhaps at somewhat deeper depths if normal faulting pervasively reduces the strength of the shallow plate. Thus in northern India we should anticipate normal faulting from say $20 \mathrm{~km}$ depth to the surface and reverse 


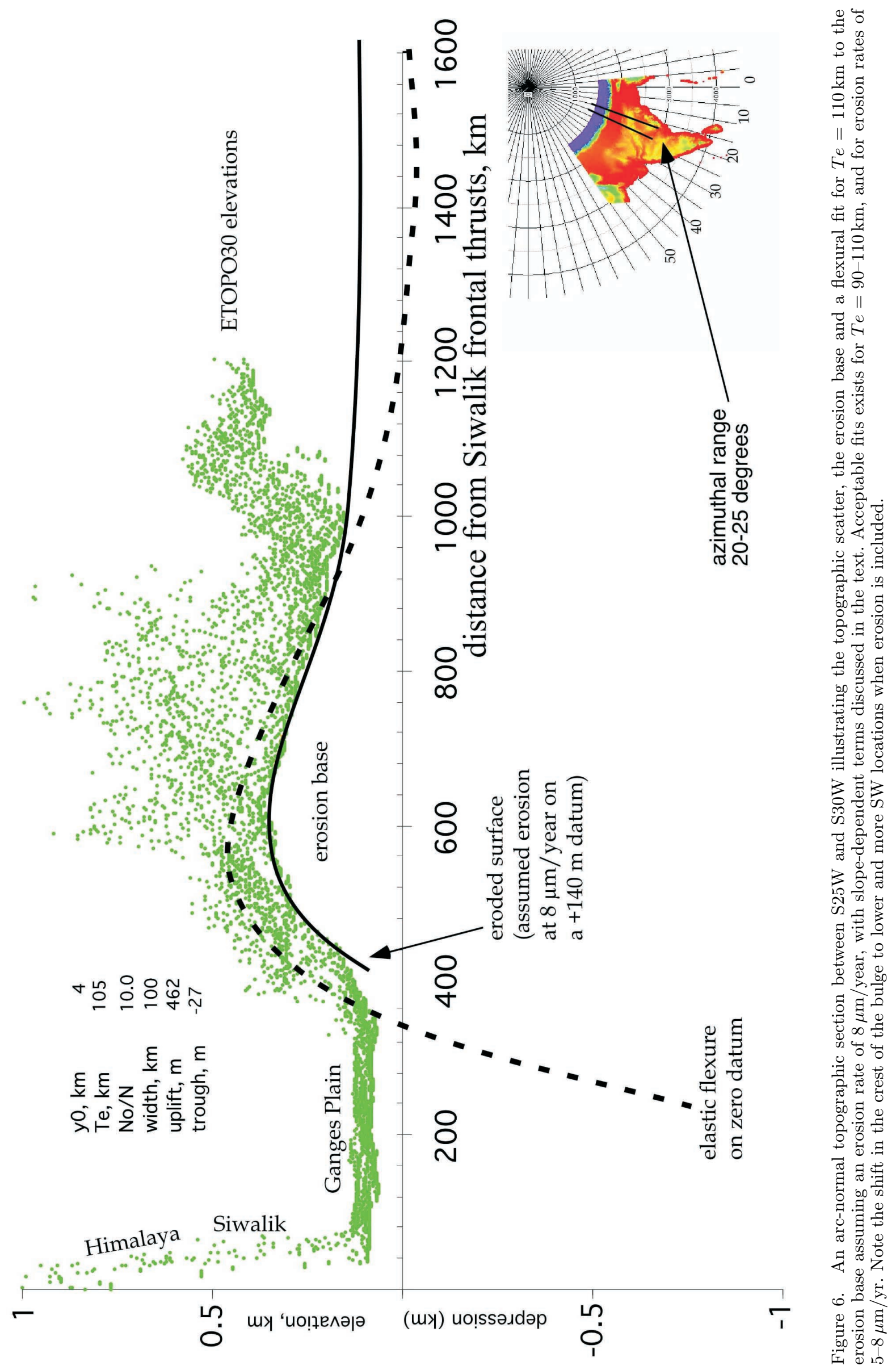




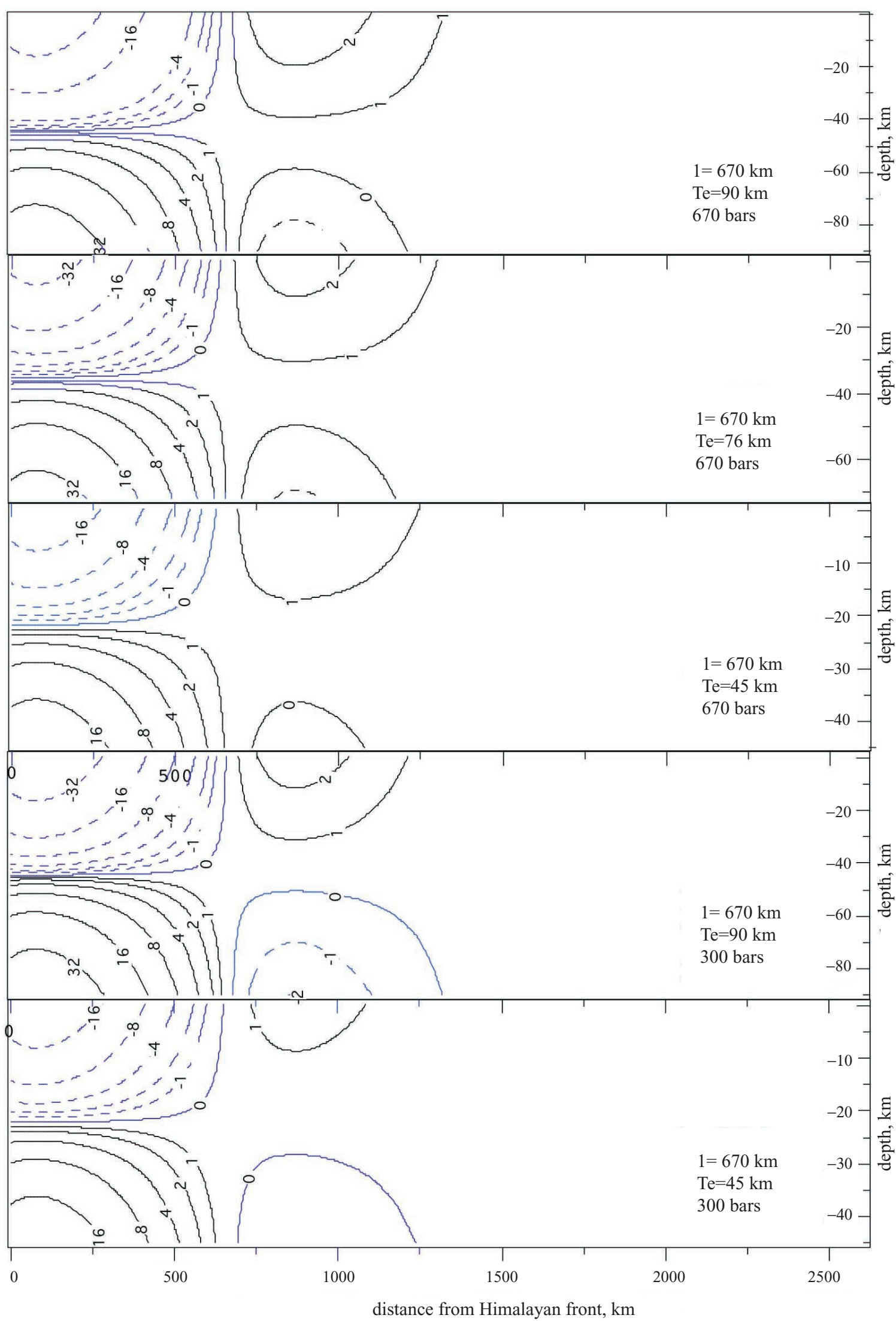

Figure 7. Stress distribution in a bent plate with a $670 \mathrm{~km}$ wavelength bulge. Contours are shown for three different elastic thicknesses, and for two different end-loading stresses. Contours are shown in kbar for 670 bar $(N o / N=100)$ end loading, and for $300 \operatorname{bar}(N o / N=300)$ end loading. Independent of thickness, compressive surface stresses approach or exceed $1 \mathrm{kbar}$ $800-1000 \mathrm{~km}$ from the Himalaya. 
faulting below these depths. We should anticipate reverse faults throughout the Indian crust in southern India. Immediately south of the flexural bulge in the outer-moat, however, we should anticipate reverse faulting near the surface, but normal faulting at depth.

Published focal mechanisms (Molnar et al 1977; Molnar and Chen 1983; Chen and Kao 1996) are consistent with these essential features of the stress field. Normal faulting earthquakes occur at shallow depths in the Ganges Plain (7 August 1966, Molnar et al 1977), similar in mechanism and setting to Aleutian earthquakes (Stauder 1968). The Udaypur 1988 earthquake reveals compression at $40 \mathrm{~km}$ beneath the Himalaya (Chen and Kao 1996) and normal faulting occurs near and above this event (Jackson 2002). The Jabalpur earthquake was a deep reverse faulting event that occurred near the crest of the flexural bulge (Chen and Kao 1996).

The largest intracratonic events of the past 200 years, however, are apparently inconsistent with the predictions of the $40 \mathrm{~km}$ thick plate model: the 1897 Assam and 2001 Bhuj reverse faulting events.

The 1897 great Assam earthquake ruptured in a reverse sense implying compression from $40 \mathrm{~km}$ to $9 \mathrm{~km}$ depth (Bilham and England 2001). This suggests that, as anticipated, the surface of the plate in this region is in tension and was unable to sustain shallow reverse faulting. The 1897 rupture presumably started in a region of compression at depth and may have approached and passed the neutral axis, but was unable to rupture into the region of tensile stress. However, normal faulting on the surface $(10 \mathrm{~m}$ of slip on the Chedrang Fault) was orthogonal to the main rupture plane and is thus inconsistent with the view that surface stress should be tensional in a NNE/SSW direction. We note however, that evidence for a Himalayan-induced flexural bulge is absent at the longitude of Bangladesh so that the setting of this earthquake may be anomalous compared to earthquakes elsewhere in the Indian plate.

Aspects of the Bhuj 2001 event are also somewhat inconsistent with our estimate of flexural stresses calculated for the Gujarat region. Although the earthquake ruptured in a reverse sense, as expected in the region south of the flexural bulge near the flexural trough, we note that theory dictates highest stresses should prevail at the surface The Bhuj rupture and its aftershocks appear to be largely confined below $9 \mathrm{~km}$ (Schweig et al 2003). It is possible that the Anjar earthquake of 1956, and possibly earlier earthquakes in the previous century, had already released surface compression in the Kachchh region, thus loading the subsurface, and effectively lowering the region of maximum compressive stress.
In figure 5 we plot both numbers of earthquakes and their energy release in 100-km-wide bins as a function of distance across the flexural bulge. We note that although the maximum number of earthquakes occurs near the locking line in the Himalaya, the maximum energy release for the time period 1960-98 occurs near the flexural bulge and outer trough. We interpret this to signify that the release of compressional strain energy occurs as those portions of the Indian plate first encounter increased compressional stress in their northward motion toward the Himalaya.

\section{Discussion}

\subsection{Stress distribution}

The stress field resulting from flexure overwhelms the in-plane stresses within $1000 \mathrm{~km}$ of the continental collision, thereby dominating the tectonic setting of earthquakes in the northern Indian plate. The upper and lower surfaces of the plate experience approximate antisymmetric stress distributions with the largest stresses in the northern $250 \mathrm{~km}$ of the flexed plate. Although the spatial pattern of stress variation can be constrained to within $100 \mathrm{~km}$ from the geometry of the flexural bulge, the absolute values of these stresses depend on several assumptions about plate loading, inferred ambient stresses, and the elastic thickness of the Indian plate. Maximum estimates vary from $2 \mathrm{kbar}$ in the outer moat, to more than $20 \mathrm{kbar}$ beneath the northern Ganges plain. We assume that stresses in the absence of flexure are 300700 bars. If we assume that support of the bulge is obtained at least in part from dynamic flow in the mantle, these stresses may be reduced by an order of magnitude, but the geometrical distribution of stress gradients is assumed to be similar. This assumption, however, needs to be tested in future analyses.

The vertical gradient of stress is independent of the elastic thickness since the fiber stress is proportional to the distance from the neutral axis for the given curvature. Maximum vertical gradients beneath the Himalayan foothills are approximately $+0.5 \mathrm{kbar} / \mathrm{km}$ whereas in the outer trough they do not exceed $-0.05 \mathrm{kbar} / \mathrm{km}$ (the negative sign indicating decreasing compressive stress with depth). In contrast, the horizontal gradients in stress depend on the elastic thickness and are quantified below.

A zone of zero stress - the neutral axis-separates the region of compression from the region of tension. In a bent plate not subject to in-plane loading, the neutral axis would lie half way through 


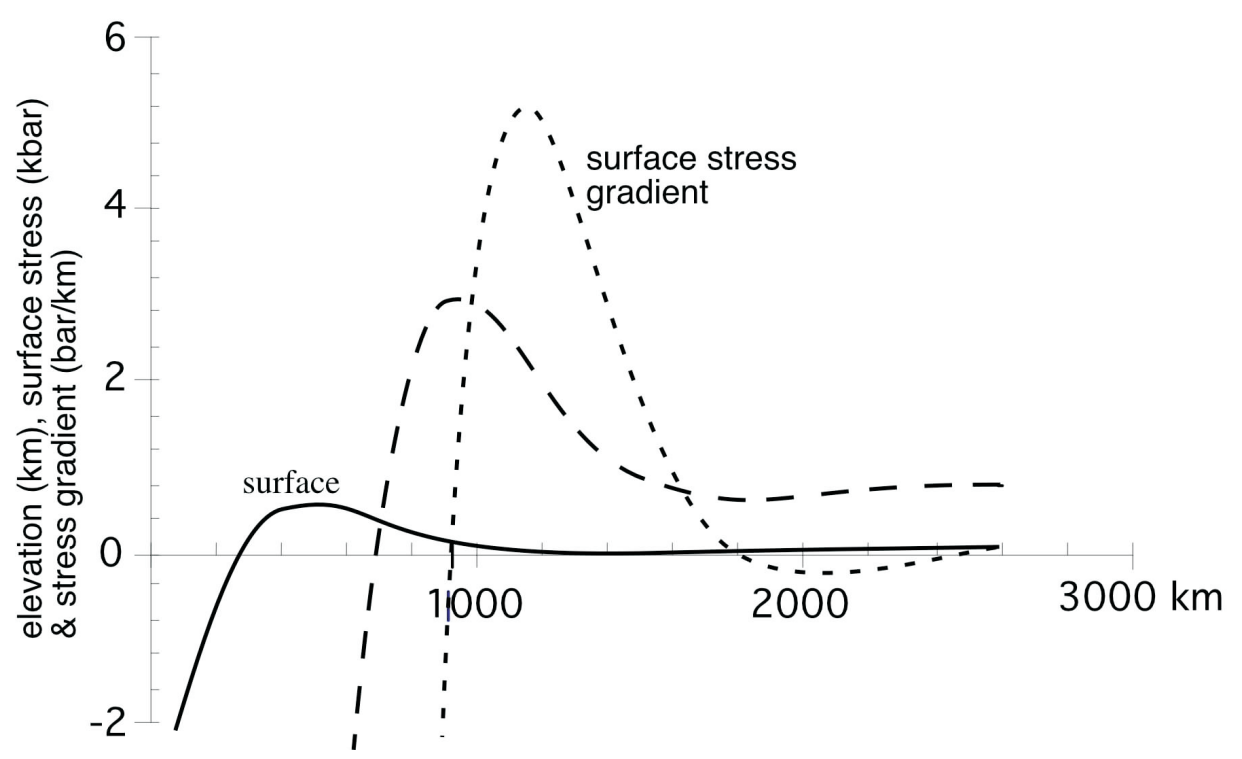

Figure 8. Variation of elevation (solid line), stress (dashed line) and spatial rate of change of stress (dotted line) on the surface of a $90 \mathrm{~km}$ thick Indian plate. Note that in central India, south of the crest of the flexural bulge, the stress increases by more than 4 bars per $\mathrm{km}$. The stresses are numerically $44 \%$ smaller in a $40 \mathrm{~km}$ thick plate.

the plate. Collisional stresses place the flexed Indian plate in compression and raise the neutral axis to the surface throughout much of the plate south of the flexural bulge. However, because flexural stresses are considerably larger than inferred in-plane stresses encountered remote from the Himalaya, the neutral axis near the Himalaya is raised from a plane midway through the plate by less than $10 \%$ of the elastic thickness. For all inferred elastic thicknesses the neutral axis rises and meets the earth's surface approximately $400 \mathrm{~km}$ south of the Himalaya, slightly north of the crest of the flexural bulge.

Because the gradient of flexural stress is high in the region just south of the Himalaya, it would seem possible that observations of stress indicators here would settle the controversy concerning the elastic thickness of the Indian plate. Earthquakes above and below the neutral axis will occur with opposite mechanisms. Thus, only if the elastic thickness is greater than $40 \mathrm{~km}$ will normal faulting earthquakes occur below a depth of $20 \mathrm{~km}$ near the Himalaya. Focal mechanisms that might settle this controversy are currently unavailable.

\subsection{Rates of change of stress}

The range of peak compression to peak tensile stress depends on the plate thickness and prevailing boundary conditions, and in some models exceeds \pm 30 kbar. It is likely that plastic flow will reduce compressional stresses at depth and fracturing will reduce tensile stresses near the surface, resulting in an effective thinning of the elastic plate. The models of Melosh and Raefsky (1908) favor stresses of less than $2 \mathrm{kbar}$. The time taken for points in India to be translated through this transition exceeds 32 million years, so stress changes from year-toyear are small. The maximum temporal change in surface stress as India is translated through the flexural stress field is less than $1 \mathrm{mbar} / \mathrm{yr}$ or $1 \mathrm{bar} /$ millennium. The incremental change in stress per unit time is thus insignificant, much slower than proposed triggering mechanisms for earthquakes. Thus the change in stress per unit time is of secondary importance compared to stress changes produced by other earthquakes, for example.

In contrast the spatial gradient in stress imposed on the Indian plate is of great importance for characterizing the propensity for earthquake occurrence. The spatial derivative of the stress field has units of bars per horizontal $\mathrm{km}$ and peaks approximately $300 \mathrm{~km}$ south of the peak compressional stress, and roughly $650 \mathrm{~km}$ south of the crest of the flexural bulge (figure 8). Following a minor reduction of stress $(<1 \mathrm{bar} / \mathrm{km})$ between 2600 and $1800 \mathrm{~km}$ south of the Himalaya, surface stress increases by an average $2 \mathrm{bar} / \mathrm{km}$ over the next $600 \mathrm{~km}$ with a peak spatial gradient of $5.2 \mathrm{bar} / \mathrm{km}$ for some models tested. Stresses and stress gradients would be a factor of two or more lower in a $40 \mathrm{~km}$ thick elastic plate.

\section{Conclusions}

Severe heterogeneity in stress exists within the Indian plate as a result of flexural bending caused 
by forces along its northern margin. The wavelength of the flexural bulge inferred from the gravity and geometrical properties of the Himalaya and Ganges plain $(\approx 650 \mathrm{~km})$ is consistent with the wavelength inferred directly from an inferred erosion base in the region of the Central Indian Plateau. From the crest of the flexural bulge northward, the surface is in tension. The surface of an associated trough $700-1200 \mathrm{~km}$ SSW of the Himalaya is in compression. Maximum compressional stress here are approximately double the ambient horizontal tectonic stress in the Indian plate far from the Himalaya, and are the largest compressional stresses encountered by the surface of the Indian plate as it approaches the Himalaya.

The observed distribution of earthquake focal mechanisms and the observed distribution of seismic energy release are both consistent with the inferred flexural stress field. The recent Bhuj earthquake occurred close to this region of maximum stress, as did the Latur earthquake of 1993.

Relatively minor perturbations above ambient stress levels can trigger earthquakes (e.g., 1 bar). As India moves towards Tibet, every point in India passes slowly through the flexural stress field. The rate of change of stress with time is small $(<1$ bar per millennium), and although it is responsible for bringing the Indian plate closer to regional failure, it is likely that other stress perturbations are primarily responsible for triggering specific local ruptures. The Koyna earthquake, for example, though triggered by reservoir loading, lies in the region of surface compressional stress. Not all mid-plate earthquakes in India occur in regions close to maxima in the flexural stress field, and there are clearly contributory stresses in the collisional system that must be responsible for these earthquakes. The flexural stress distribution discussed, however, lends itself to numerous seismological and geodetic tests that are outside the scope of this article.

The inferred spatial gradient of stress is surprisingly large, increasing northward at more than 2 bars per $\mathrm{km}$ towards the crest of the flexural bulge, and decreasingly even more rapidly to negative (tensile values) between the bulge and the Himalayan foothills. This, together with the observed spatial distribution in compressional and tensile stress, provides an important physical basis for seismic hazard zonation.

\section{Acknowledgements}

We thank Philip England, Vinod Gaur, James Jackson, Dan McKenzie, Geoff King, Peter Molnar, and Tony Watts for their insightful criticism of aspects of these ideas. The research was funded by the National Science Foundation EAR-0003449 and by the NASA SENH program.

\section{References}

Bendick R and Bilham R 2001 Search for buckling of the southwest Indian coast related to Himalayan collision. In: Himalaya and Tibet: mountain roots to mountain tops. (ed) A Macfarlane, R Sorkhabi, and J Quade; Geological Society of America Special Paper 328 pp 313-323

Bendick R and Bilham R 2001 How perfect is the Himalayan Arc? Geology 29 791-794

Bilham R 1988 Earthquakes and urban growth; Nature 336 625-626

Bilham R and Gaur V K 2000 Geodetic contributions to the study of seismotectonics in India; Curr. Sci. 7991259 1269

Bilham R and England P 2001 Plateau pop-up during the great 1897 Assam earthquake; Nature 410 806-809

Bilham R, Larson K, Freymueller J and Project Idylhim members 1997 GPS measurements of present-day convergence across the Nepal Himalaya; Nature (London) 386 $61-64$

Burrard S G 1901 The attraction of the Himalaya mountains upon the plumb-line in India; Survey of India Professional Paper 5 Dehra Dun, pp 115

Burrard S G 1912 On the origin of the Himalaya mountains; Survey of India Professional Paper 12 Calcutta, pp 26

Chen W-P and Kao H 1996 Seismotectonics of Asia: some recent progress, in the tectonic evolution of Asia, (ed) An Yin and T M Harrison; Cambridge Universiy Press, 37-54

Cowie H McC 1921 A criticism of Mr. R. D. Oldham's memoir "the structure of the Himalayas and of the Gangetic Plain as elucidated by geodetic observations in India"; Survey of India Professional Paper 18 Dehra Dun, pp 33

Dmowska R, Zheng G and Rice J R 1996 Seismicity and deformation at convergent margins due to heterogeneous coupling; J. Geophys. Res. 101 3015-3029

Engdahl R, van der Hilst R and Buland R 1997 Global teleseismic earthquake relocation with improved travel times and procedures for depth determination; Bull. Seism. Soc. Am. $88722-743$

Glennie E A 1931 Gravity; Survey of India Geodetic Report, VI 52-64, Dehra Dun

Goudie A 1995 The changing earth, rates of geomorphological Processes (Blackwell) pp 302

Gowd T N, Srirama Rao S V and Gaur V K 1992 Tectonic stress field in the Indian subcontinent; J. Geophys. Res. 97 (B8), 11879-11888

Jackson J 2002 Strength of the continental lithosphere: time to abandon the jelly sandwich?; GSA Today 12 (9) $4-9$

Jain S C, Nair K K K and Yedekar D B 1995 Geology of the Son-Narmada-Tapti Lineament Zone in Central India. In: Project Crumansonata: Geoscientific Studies of the SonNarmada-Tapti Lineament Zone; Geol. Surv. India, Sp. Pub. 10 1-154

Karner G D and Watts A B 1983 Gravity anomalies and flexure of the lithosphere at mountain ranges; J. Geophys. Res. 88 10449-10477

Kenner S J 2001 How faults are loaded: the influence of tectonic environment; American Geophysical Union Fall Meeting, EOS Fall Meeting Supplemental, 82 F942 December 2001

King G C P and Bilham R G 1973 Strain measurement instrumentation and technique; Philosophical transactions of the Royal Society of London, A274 209-217 
Lyon-Caen H and Molnar P 1985 Gravity anomalies, flexure of the Indian plate, and the structure, support and evolution of the Himalaya and Ganga basin; Tectonics 4 513-538

Lyon-Caen H and Molnar P 1983 Constraints on the structure of the Himalaya from an analysis of gravity anomalies and a flexural model of the lithosphere; $J$. Geophys. Res. 88 8171-8191

Maggi A, Jackson J A, McKenzie D and Priestley K 2000 Earthquake focal depths, effective elastic thickness, and strength of the continental lithosphere; Geology 28 495498

Maggi A, Jackson J A, Priestley K, Baker C 2000 A reassessment of focal depth distributions in southern Iran, the Tien Shanand northern India: Do earthquakes really occur in the continental mantle? Geophys. J. Int. 143 $629-661$

McKenzie D and Fairhead D 1997 Estimates of the effective elastic thickness of the continental lithosphere from Bouguer and free-air gravity anomalies; J. Geophys. Res. 102 27523-27552

Melosh H J 1978 Dynamic support of the outer rise; Geophys. Res. Lett. 5 321-324

Melosh and Raefsky 1908 The dynamical origin of subduction zone topography; Geophys. J. R. Ast. Soc. 60333 354

Molnar P, Chen W-P, Fitch T J, Tapponier P, Warsi W E K and Wu F T 1977 Structure and tectonics of the Himalaya: a brief summary of relevant geophysical observations. In: Himalaya: Sciences de la Terre. pp 269-294. Editions du Centre National de la Recherche Scientifique, Paris

Molnar P and Chen W-P 1983 Focal depths and fault plane solutions of earthquakes under the Tibetan plateau; $J$. Geophys. Res. 88 1180-1196

Oldham R D 1917 The structure of the Himalayas and of the Gangetic Plain, as elucidated by geodetic observations in India; Mem. Geol. Survey of India XLII(2) Calcutta

Parsons B and Molnar P 1976 The origin of the outer topographic rises associated with trenches; Geophys. J. Roy. Astr. Soc. 45 pp 707

Paul J, Burgmann R, Gaur V K, Bilham R, Larson K M, Ananda M B, Jade S, Mukul M, Anupama T S, Satyal G,
Kumar D 2001 The motion and active deformation of India; Geophys. Res. Lett. 28 (4) 647-651

Rapp R H, Yan Ming Wang, Pavlis N K, Aug. 1991 The Ohio State 1991 Geopotential and sea surface topography harmonic coefficient models, Report No. 410, Department of Geodetic Science and Surveying, Ohio State University, Columbus Ohio 43210-1247

Sastri V V, Bhandari L L, Raju A T R and Datta A K 1971 Tectonic framework and subsurface strigraphy of the Ganga Basin; J. Geol. Soc. Ind. 12 222-233

Schweig E, III, Gomberg J, Petersen M, Ellis M, Bodin P, Mayrose L and Rastogi B K 2003 The M 7.7 Bhuj earthquake: Global lessons for earthquake hazard in intraplate regions; J. Geol. Soc. India 61, 277-282

Seeber L and Gornitz V 1983 River profiles along the Himalayan arc as indicators of active tectonics; Tectonophysics 92 335-367

Stauder W 1968 Tensional character of earthquake Foci beneath the Aleutian trench with relation to sea floor spreading; J. Geophys. Res. 73 7693-7703

Stein S, Sella G and Okal E 2002 The January 26, 2001 Bhuj earthquake and the diffuse western boundary of the Indian plate, in Plate Boundary Zones (ed) S. Stein and J Freymueller; Geodynamics Series 30, AGU, Washington $\mathrm{D} \mathrm{C}$

Taylor M A J, Dmowska R and Rice J R 1998 Upper plate stressing and seismicity in the subduction earthquake cycle; J. Geophys. Res. 103 24523-24542

Triep E G and Sykes L R 1997 Frequence of occurrence of moderate to great earthquakes in intracontinental regions; J. Geophys. Res. 102 9923-9948

Turcotte D L and Schubert G 1983 Geodynamics; Cambridge University Press

Wang Qi, Pei-Zhen Zhang, Freymueller J T, Bilham R, Larson K M, Xi'an Lai, You X, Niu Z, Wu J, Li Y, Liu J, Yang Z, Chen Q 2001 Present day crustal deformation in China constrained by global positioning measurements; Science 294 574-577

Warsi W E K and Molnar P 1977 Gravity anomalies and plate tectonics in the Himalaya. In: Himalaya: Sciences de la Terre. pp 463-473. Editions du Centre National de la Recherche Scientifique, Paris

Watts A B 2001 Isostacy and flexure of the lithosphere pp 458 (Cambridge) 